\title{
High Burn-up Structure in Nuclear Fuel: Impact on Fuel Behavior
}

\author{
Jean NOIROT ${ }^{1}$, Yves PONTILLON ${ }^{1}$, Jérôme LAMONTAGNE ${ }^{2}$, Isabelle ZACHARIE- \\ AUBRUN $^{1}$, Karine HANIFI ${ }^{1}$, Philippe BIENVENU ${ }^{1}$, Lionel DESGRANGES ${ }^{3}$ \\ ${ }^{1}$ CEA-DEN-DEC, Service d'Analyses et de Caractérisation du Comportement des Combustibles, SA3C (Cadarache, France) \\ ${ }^{2}$ CEA-DEN-DEC, Service Fabrication, Elaboration et Reconditionnement des Combustibles, SFER (Cadarache, France) \\ ${ }^{3}$ CEA-DEN-DEC, Service d'Etudes et de Simulation du Comportement des Combustibles, SESC (Cadarache, France)
}

When $\mathrm{UO}_{2}$ and $(\mathrm{U}, \mathrm{Pu}) \mathrm{O}_{2}$ fuels locally reach high burn-up, a major change in the microstructure takes place. The initial grains are replaced by thousands of much smaller grains, fission gases form micrometric bubbles and metallic fission products form precipitates. This occurs typically at the rim of the pellets and in heterogeneous MOX fuel Pu rich agglomerates. The high burn-up at the rim of the pellets is due to a high capture of epithermal neutrons by ${ }^{238} \mathrm{U}$ leading locally to a higher concentration of fissile $\mathrm{Pu}$ than in the rest of the pellet. In the heterogeneous MOX fuels, this rim effect is also active, but most of the high burn-up structure (HBS) formation is linked to the high local concentration of fissile $\mathrm{Pu}$ in the Pu agglomerates. This $\mathrm{Pu}$ distribution leads to sharp borders between HBS and non-HBS areas (Fig.1).

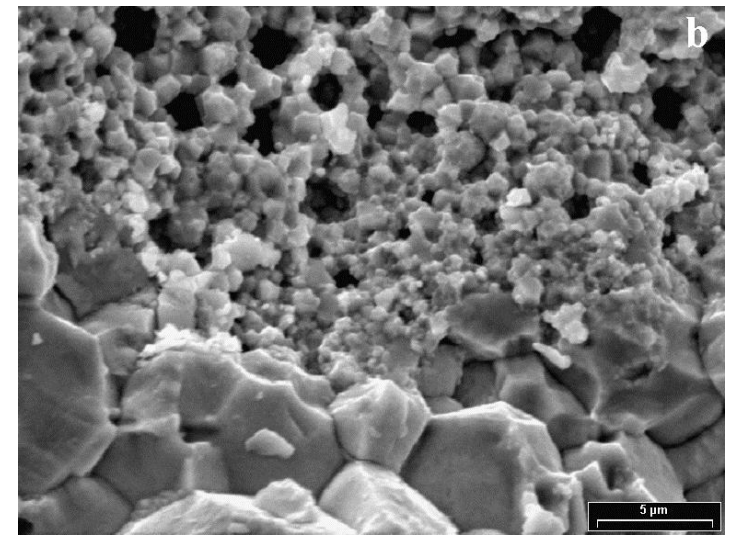

Fig. 1: Sharp limit between HBS and non-HBS areas in a $55 \mathrm{GWd} / \mathrm{t}_{\mathrm{HM}}$ MOX MIMAS fuel (from [1]).

In these MOX fuels, the HBS forming at various radial positions, and not only at the rim, it was shown that the size of the new grains, of the bubbles and of the precipitates increase with the irradiation local temperatures. Other parameters have been shown to have an influence on the HBS initiation threshold, such as the irradiation density rate, the fuel composition with an effect of the Pu presence, but also of the $\mathrm{Gd}$ concentration in poisoned fuels, some of the studied additives, like $\mathrm{Cr}$, and, maybe some of the impurities. However, not all the differences in the $\mathrm{UO}_{2} \mathrm{HBS}$ rim extent measured by different teams on various fuels have been explained [2-3]. The effect of impurities may be the main reason for these differences, but it has not been documented enough yet. It has been shown recently, with examinations of a $\mathrm{UO}_{2}$ fuel in which ${ }^{235} \mathrm{U}$ was heterogeneously distributed, that a high $\mathrm{Pu}$ concentration is not mandatory for HBS formation [4].

Several changes in the fuel behavior occur concomitantly with the HBS formation. An increase of the fission gas release and an increase in the fuel swelling rate are measured [3]. It was shown by indirect and direct approaches that HBS formation was not the main contributor to the increase of fission gas release at high burn-up [1, 5-6]. Indeed, studying the $\mathrm{Kr} / \mathrm{Xe}$ ratio or some isotopic ratio in the gases collected during rod puncturing and using the differences in the gas productions as a function of the radial position, it was shown that the HBS areas were not the main source of the released gases. SIMS measurements of the local retention confirmed this trend. Nonetheless, the formation of a strong bonding between the fuel pellet periphery and the inner surface of the cladding, with the formation of the inner zirconia layer induces tensile stresses in the fuel during power 
decrease periods. This leads to radial cracking of the rim and, consequently, to some fission gas release. The amount of gases released by this mechanism never was evaluated. HBS formation does participate to fuel swelling increase, but it is not the only phenomenon involved, other areas showing also gas bubble formation. It must be noted that all porosity observed is not new, a local decrease of the large fabrication pores being measured. The pressure in the HBS bubbles has been evaluated. At $650 \mathrm{~K}$, it is about $78 \mathrm{MPa}$, and decreases with the increasing burn-up. This corresponds to an average atomic volume of $\sim 150 \AA^{3}$, i.e. more than three times the $\cup_{2} \mathrm{O}_{2}$ trivacancy volume, hence the increase in the swelling [1].

Impact of HBS on the fuel behavior during ramp on high burn-up fuels is unclear. The generalized fuel to cladding contact prior to the ramp is certainly the major parameter. HBS may play a role, but no direct evidence of that was found, though, prior to the ramps, high strain of the HBS can be seen in the large fabrication pores decrease as well as on free surface HBS major swelling. In loss of coolant accident (LOCA) type conditions, out of pile heating tests on fuel sections as well on specially designed experimental discs have shown, like during in-pile LOCA tests, the fragmentation of HBS [7-8]. The areas prone to fragmentation are the HBS areas but also the high precipitation areas [9].

The particular power history of the heterogeneous $\mathrm{UO}_{2}$, with an increase in the linear powers at high burn-up, led to a generalized fission gas release of the HBS spot bubbles. In addition, a generalized opening of grain boundaries is evidenced by Cs departures and deposits [4].

It could therefore be interesting to design a fuel that would be particularly resistant to HBS formation and to gas precipitation into large bubbles at high temperature.

A large grain $\mathrm{UO}_{2}$ fabricated by NFD (Japan), with a long oxidizing sintering, was shown to be locally highly resistant both to bubble formation at high temperature and to HBS [10]. Expanding this to the whole fuel is an appealing idea.

\section{References}

[1] J. Noirot, L. Desgranges, J. Lamontagne, Detailed characterisations of high burn-up structures in oxide fuels, Journ. of Nucl. Mater. 372: 318-339, 2008.

[2] R. Manzel, C.T. Walker, EPMA and SEM of fuel samples from PWR rods with an average burnup of around $100 \mathrm{MWd} / \mathrm{kg}_{H M}$, Journ. of Nucl. Mater. 301: 170-182, 2002.

[3] J. Noirot, I. Aubrun, L. Desgranges, K. Hanifi, J. Lamontagne, B. Pasquet, C. Valot, P. Blanpain, $\mathrm{H}$. Cognon, High Burnup Changes in $\mathrm{UO}_{2}$ fuels irradiated up to $83 \mathrm{GWd} / \mathrm{t}$ in $\mathrm{M} 5$ Claddings, Nuclear Engineering and Technology 41: 155-162, 2009.

[4] J. Noirot, J. Lamontagne, N. Nakae, T. Kitagawa, Y. Kosaka, T. Tverberg, Heterogeneous UO2 fuel irradiated up to a high burn-up: Investigation of the HBS and of fission product releases, Journ. of Nucl. Mater. 442: 309-319, 2013.

[5] J. Noirot, L. Desgranges, P. Marimbeau, Contribution of the rim to the overall fission gas release: what do isotopic analyses reveal. Fission Gas Behaviour in Water Reactor Fuels, NEA, Ed. NEA/OECD, Cadarache (France), 2000; Vol. NEA \#03053, 2002, p 223.

[6] N. Itagaki, K. Ohira, K. Tsuda, G. Fischer, T. Ota, Fission gas release and pellet microstructure change of high burnup BWR fuel, Technical Committee meeting on advances in fuel pellet technology for improved performance at high burnup, Tokyo (Japan), IAEA.

[7] Y. Pontillon, M.P. Ferroud-Plattet, D. Parrat, S. Ravel, G. Ducros, C. Struzik, I. Aubrun, G. Eminet, J. Lamontagne, J. Noirot, A. Harrer Experimental and theoretical investigation of fission gas release from UO2 up to $70 \mathrm{GWd/t}$ under simulated LOCA type conditions: the GASPARD program LWR Fuel Performance, Orlando, September 19-22, 2004; pp 490-499, Paper 1025.

[8] J. Noirot, Y. Pontillon, S. Yagnik, J.A. Turnbull, T. Tverberg, Fission gas release behaviour of a $103 \mathrm{GWd} / \mathrm{t}_{H M}$ fuel disc during a $1200^{\circ} \mathrm{C}$ annealing test, Journ. of Nucl. Mater. 446: 163-171, 2014

[9] J. Noirot, T. Blay, J. Lamontagne, L. Fayette, Y. Pontillon, X. Pujol, Size and radial origin of fragments formed while heating a $83 \mathrm{GWd} / \mathrm{tU}$ PWR fuel up to $1200{ }^{\circ} \mathrm{C}$. LOCA Workshop, Fuel fragmentation, relocation and dispersal (FFRD), Aix-en-Provence (France), 2015.

[10] J. Noirot, Y. Pontillon, S. Yagnik, J.A. Turnbull, Post-irradiation examinations and hightemperature tests on undoped large-grain UO2 discs, Journ. of Nucl. Mater. 462: 77-84, 2015. 
DE LA RECHERCHE À L'INDUSTRIE
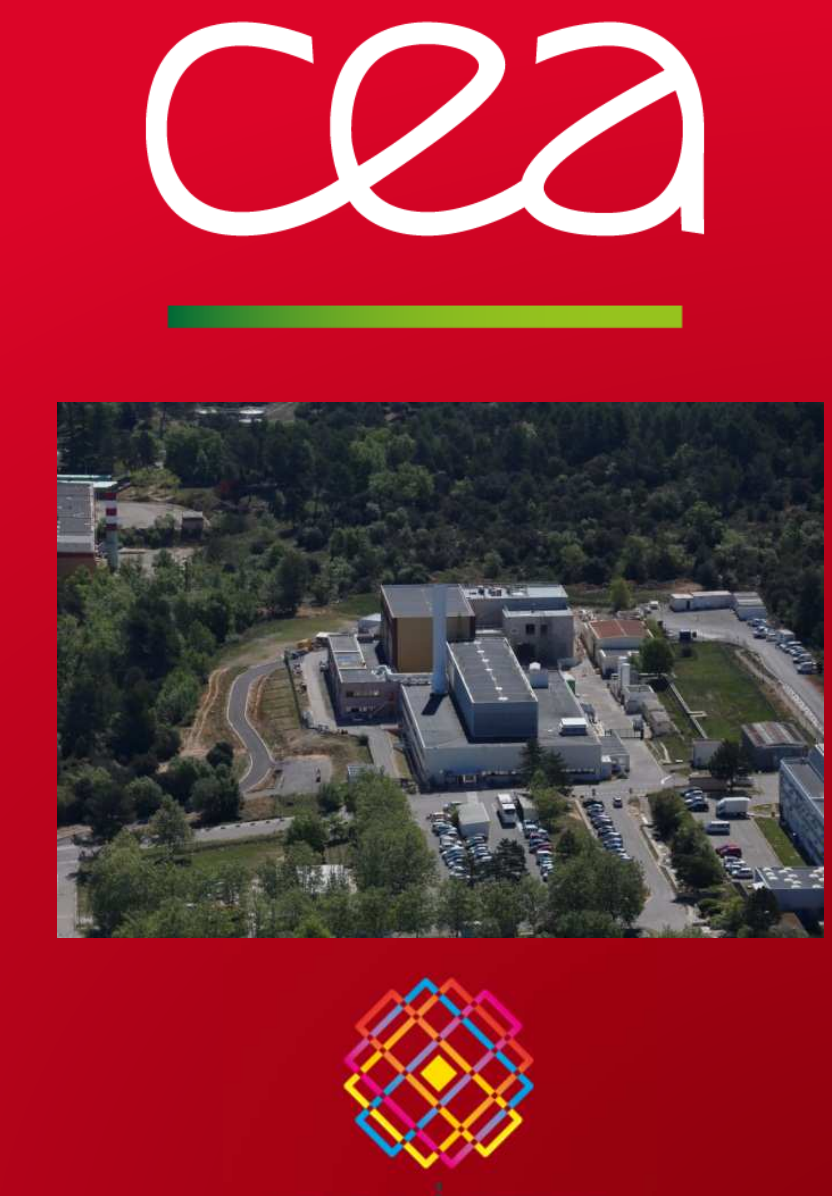

www.cea.fr

\section{MIN口S}

HIGH BURN-UP STRUCTURE IN

NUCLEAR FUEL:

IMPACT ON FUEL BEHAVIOR

\author{
J. Noirot \\ Y. Pontillon
}

J. Lamontagne

I. Aubrun K. Hanifi

Ph. Bienvenu

L. Desgranges

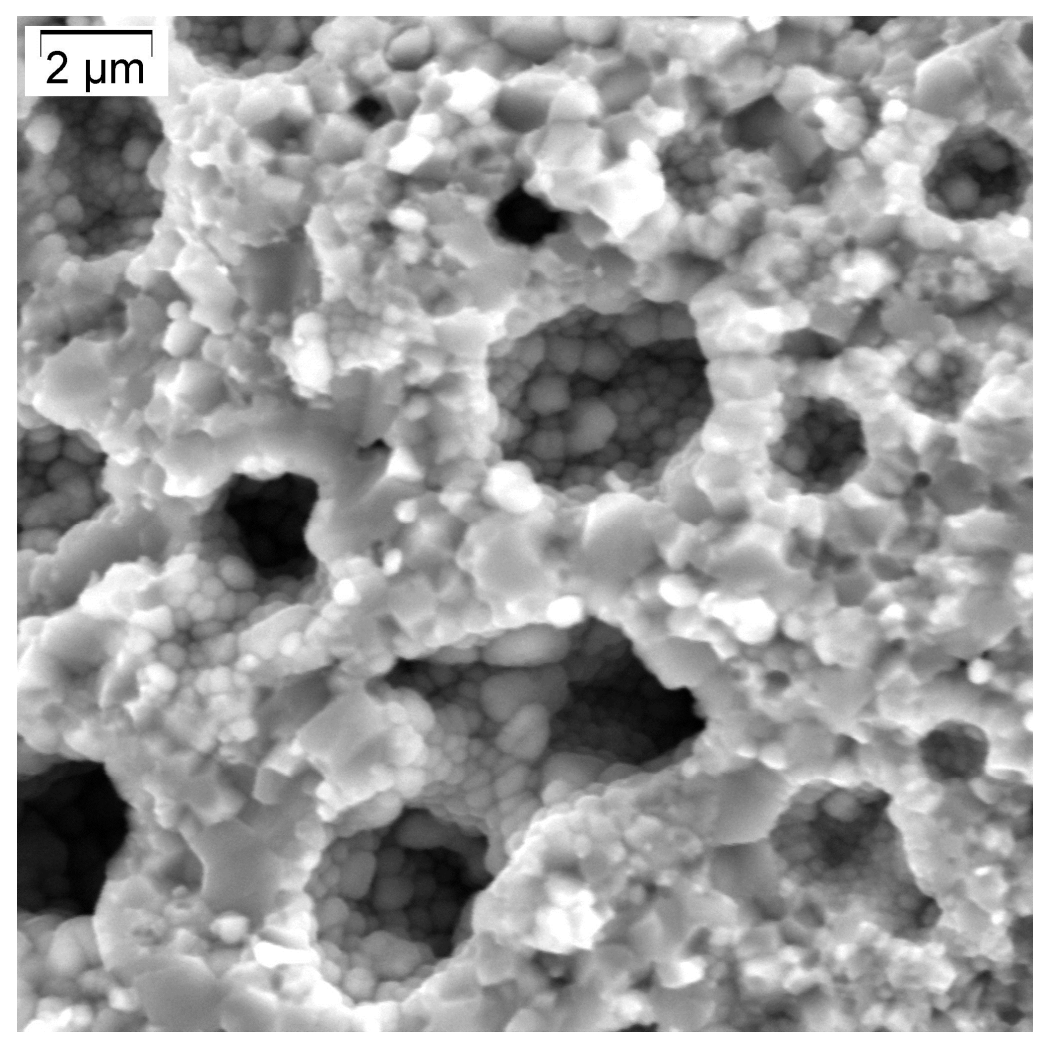




\section{cea HBS in a PWR $\mathrm{UO}_{2}$}

\section{$\because$ MINDS}

$73 \mathrm{GWd} / \mathrm{t}_{\mathrm{U}}$
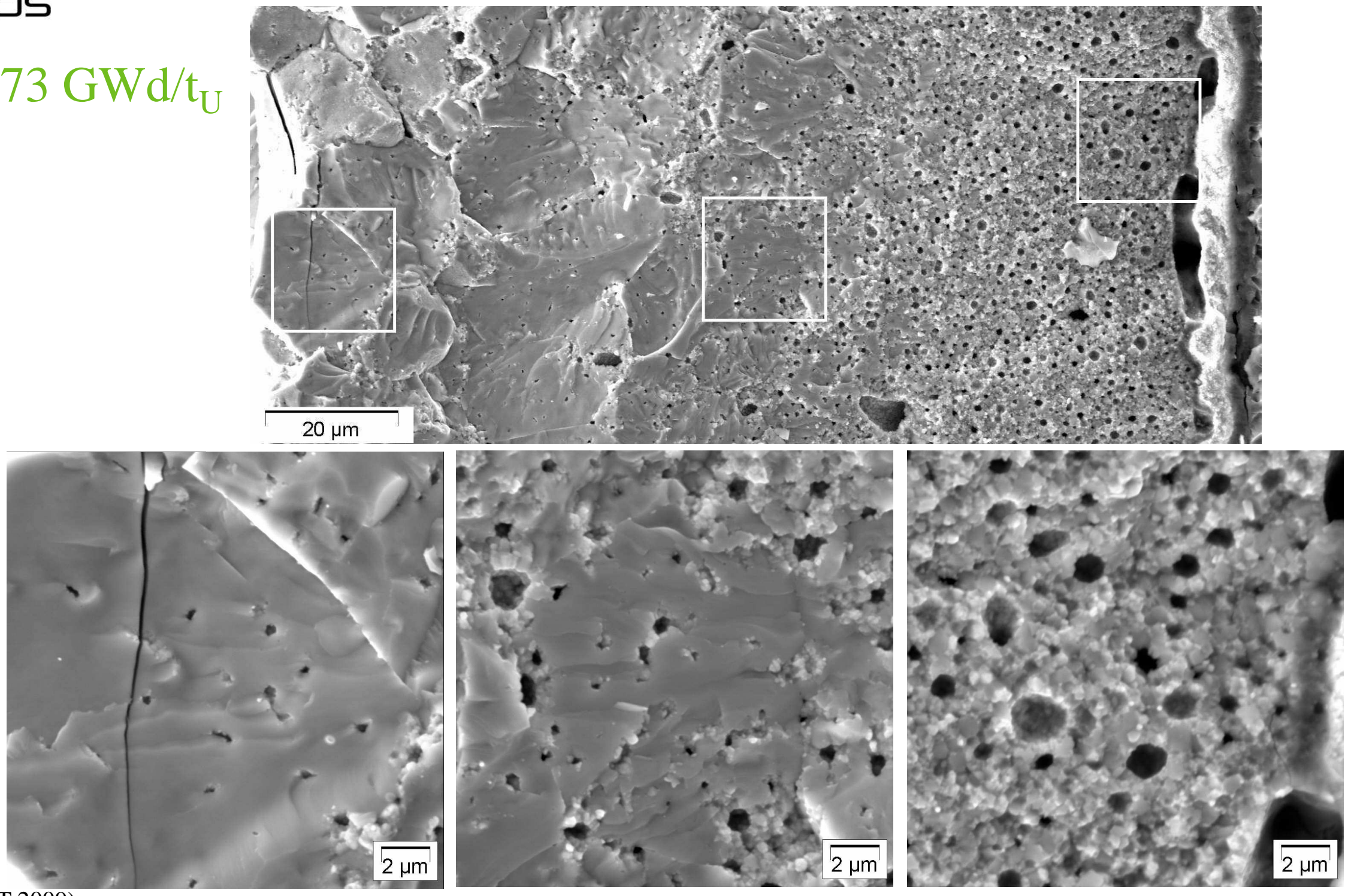


\section{why at the rim?}

\section{MIN口S}

Pu diametral profile in $\mathrm{UO}_{2}$ fuel at $50 \mathrm{GWd} / \mathrm{t}_{\mathrm{U}}$
Capture of $\mathbf{n}$ by ${ }^{238} \mathbf{U}$

$\rightarrow$ Pu build-up in $\mathrm{UO}_{2}$

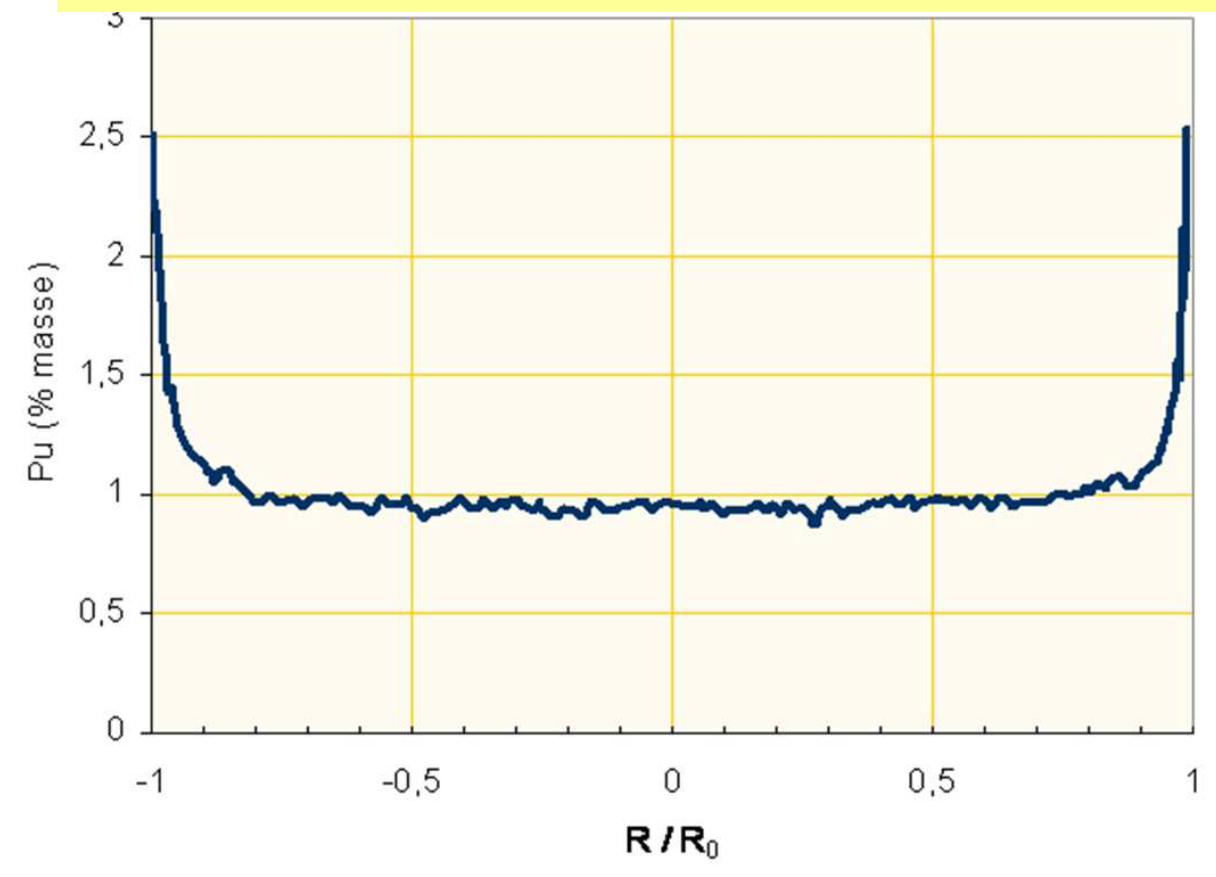

Resonance peaks for epithermal neutrons $\rightarrow$ much higher Pu build-up at pellet periphery ( $x 2$ to 3 )

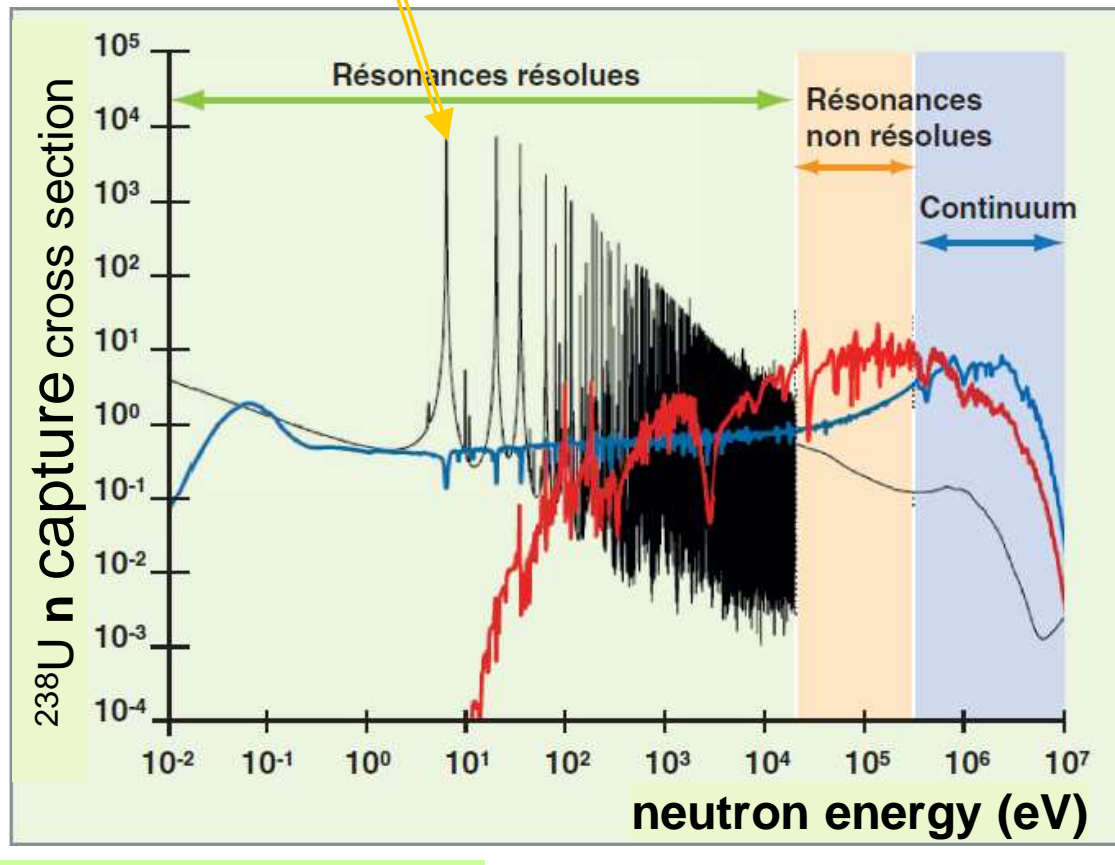

$>1000$ dpa

HBS or rim effect 


\section{cea In a heterogeneous MOX fuel}

¿MINDS Very high BU spots $\rightarrow$ HBS formation, not only at the rim

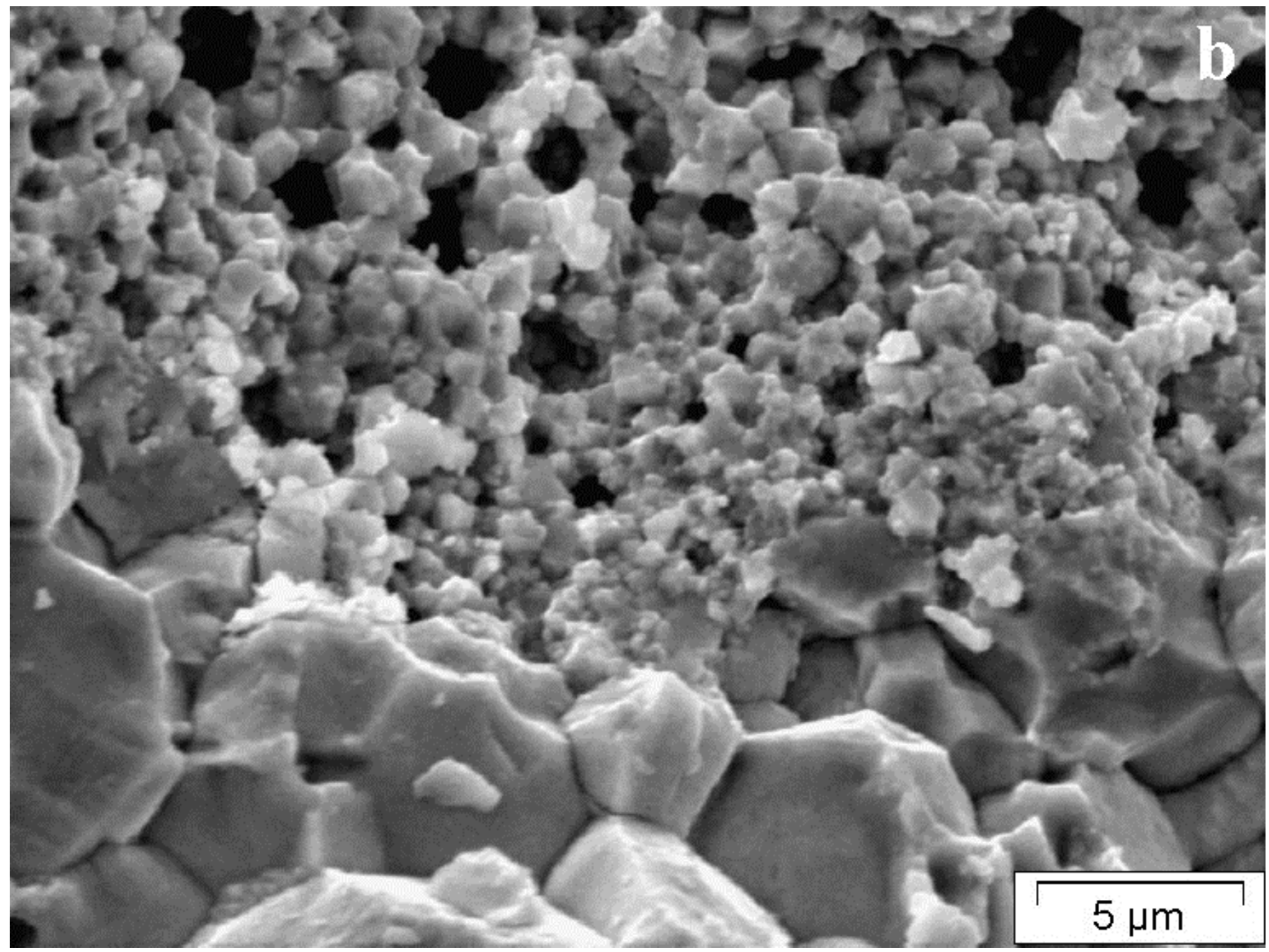




\section{cea In a heterogeneous MOX fuel}

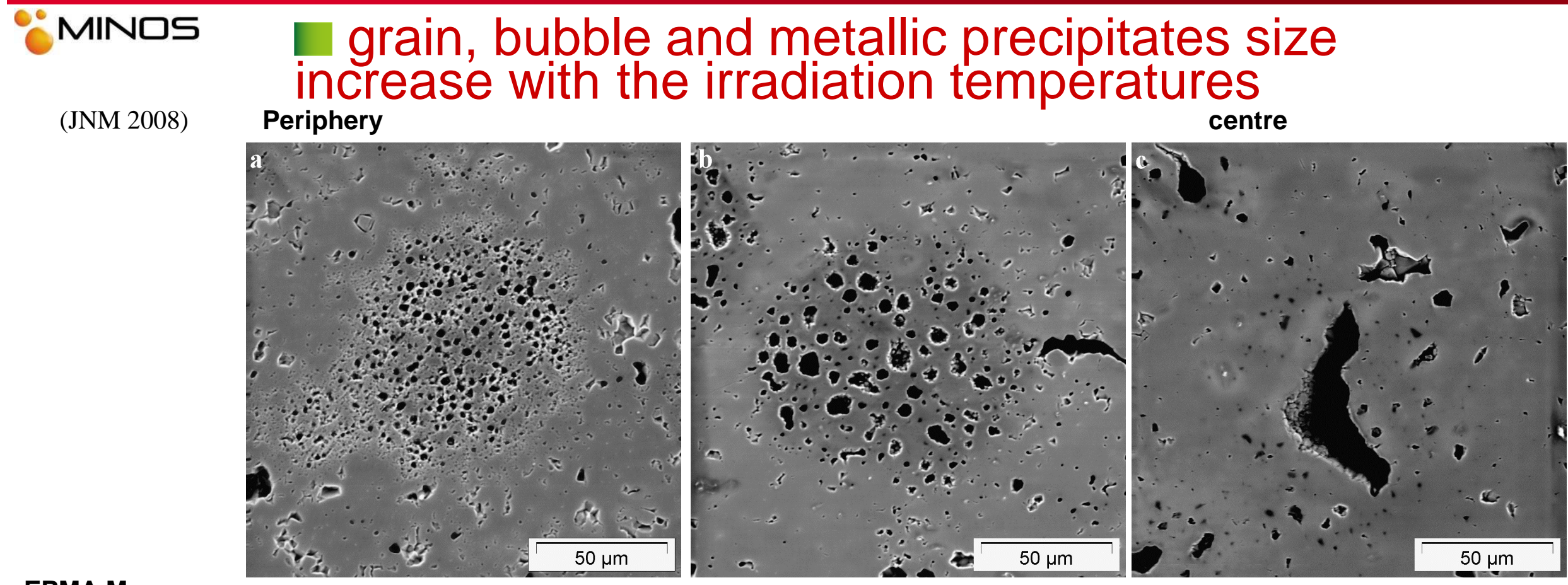

\section{EPMA Mo maps}

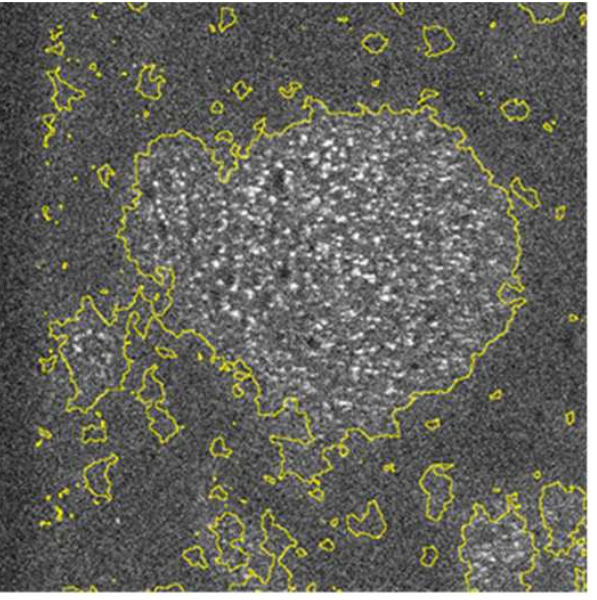

CEA - DEN

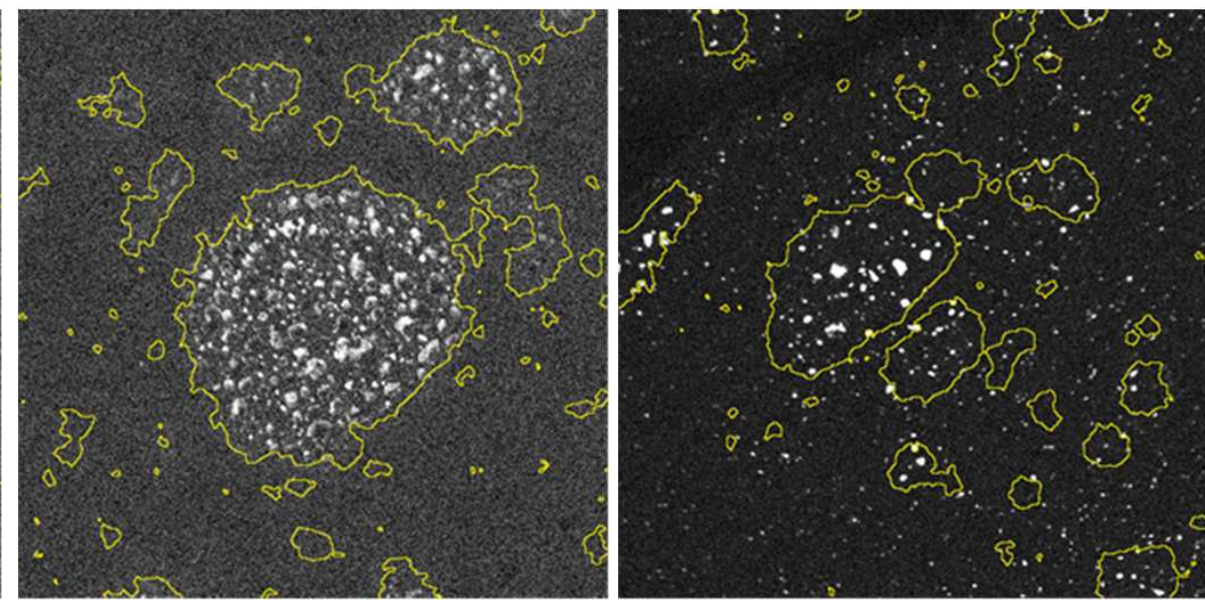

$2^{\text {nd }}$ Int. MINOS Workshop - November 4-6, 2015, CEA - INSTN Cadarache, France 


\section{cea influence on the HBS formation}

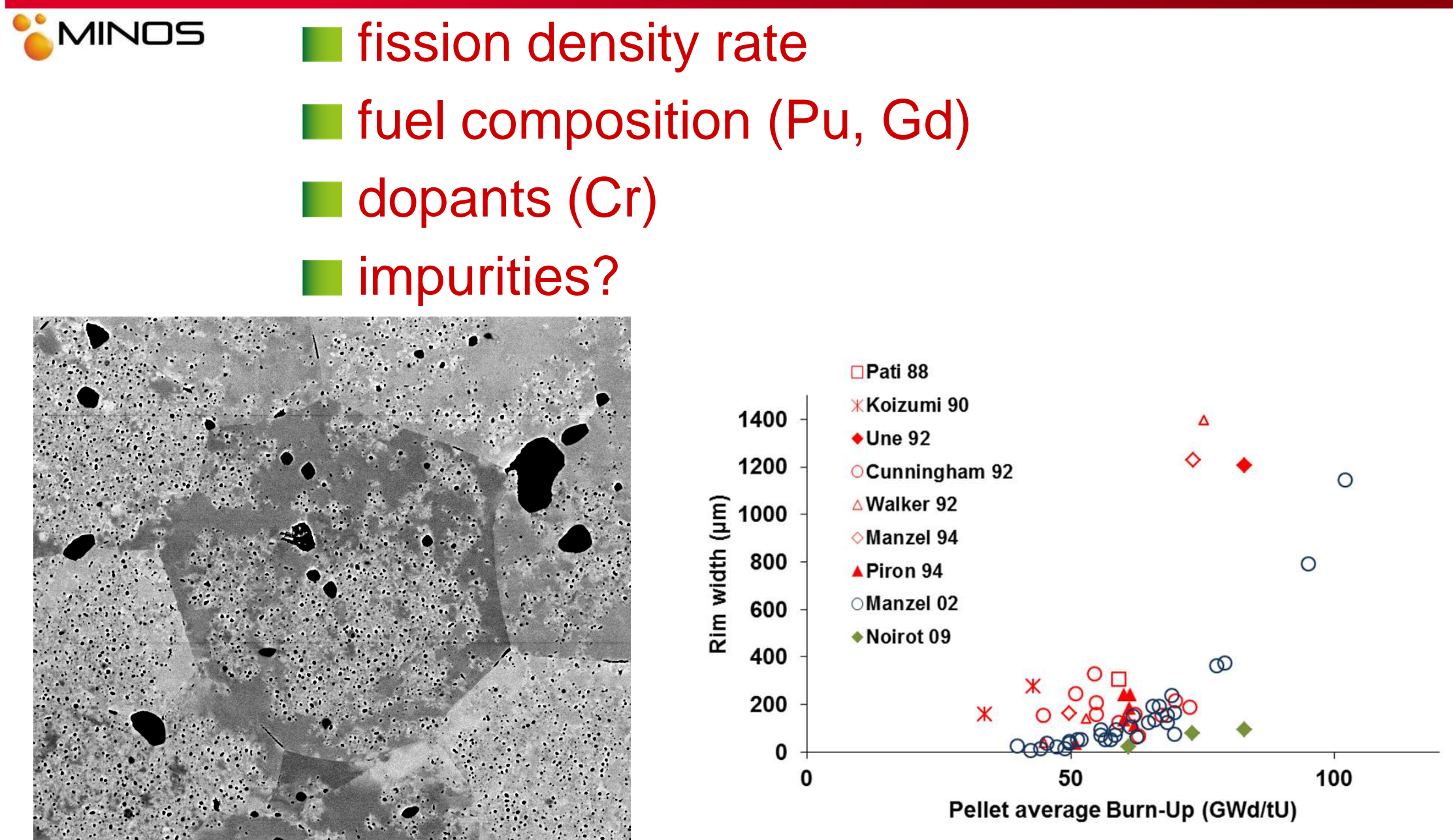

$\mathrm{Cr}_{2} \mathrm{O}_{3}$ doped $\mathrm{UO}_{2} 62 \mathrm{GWd} / \mathrm{t}_{\mathrm{U}}$ at $500 \mu \mathrm{m}$ from pellet's periphery

(D. Baron NET 2009)

6 


\section{cea High Pu is not mandatory for HBS}

\section{¿MiNas Heterogeneous $\mathrm{UO}_{2}$ case in Halden reactor}

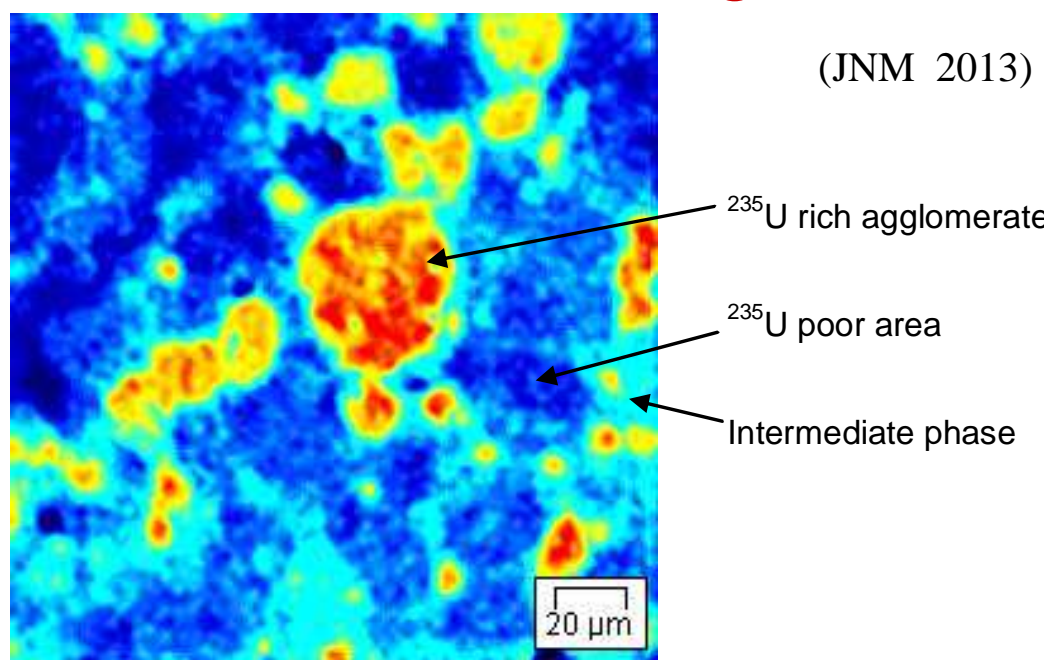

SIMS ${ }^{235} \mathrm{U}$ map

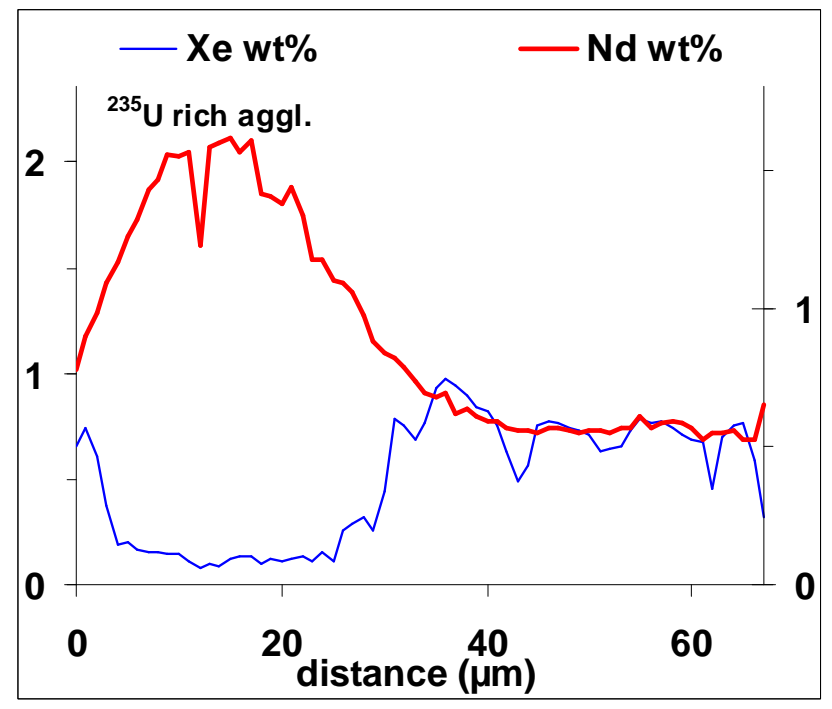

7 CEA - DEN
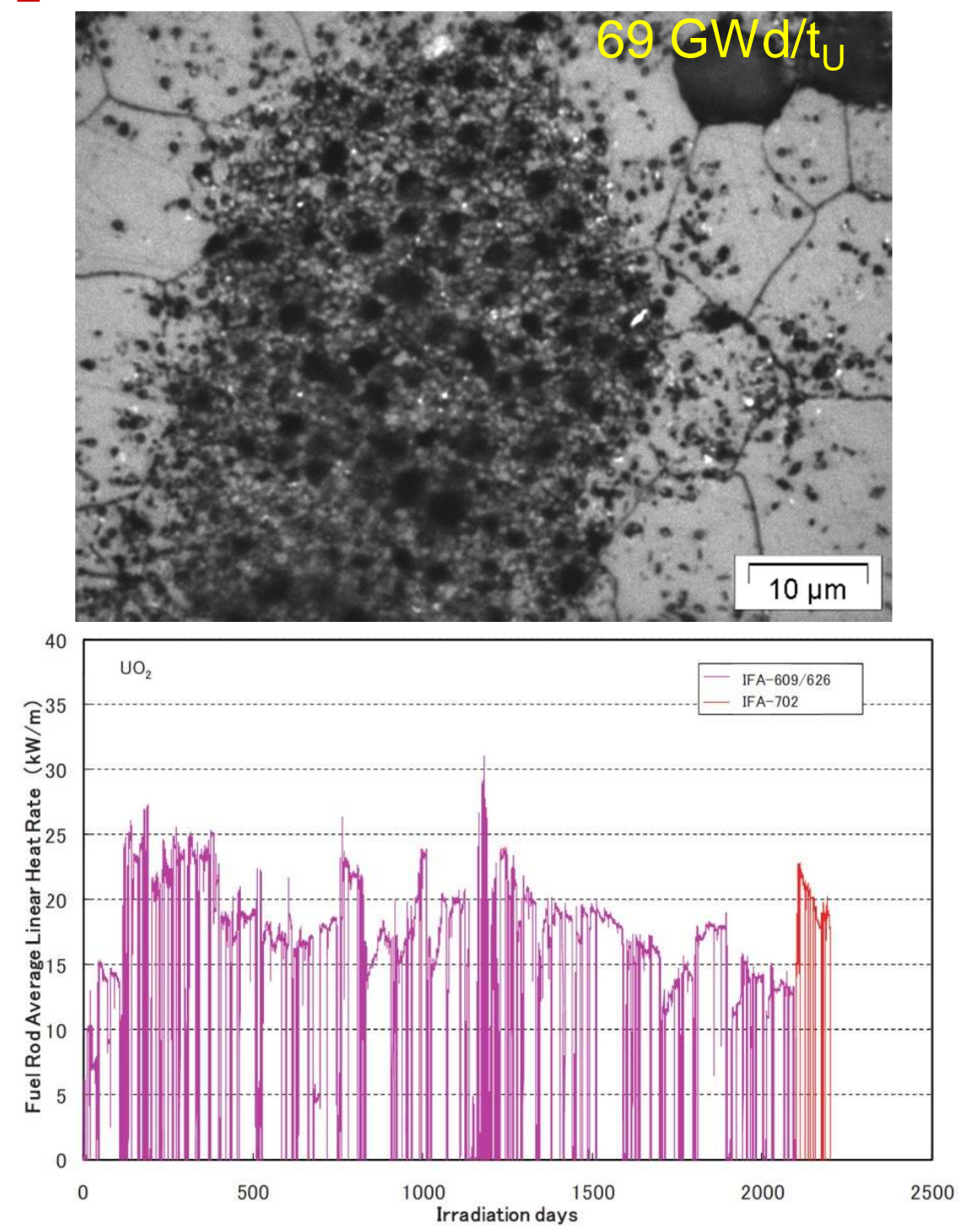

$2^{\text {nd }}$ Int. MINOS Workshop - November 4-6, 2015, CEA - INSTN Cadarache, France 


\section{cea Concomitant phenomena}

MINaS increase in the fission gas release rate

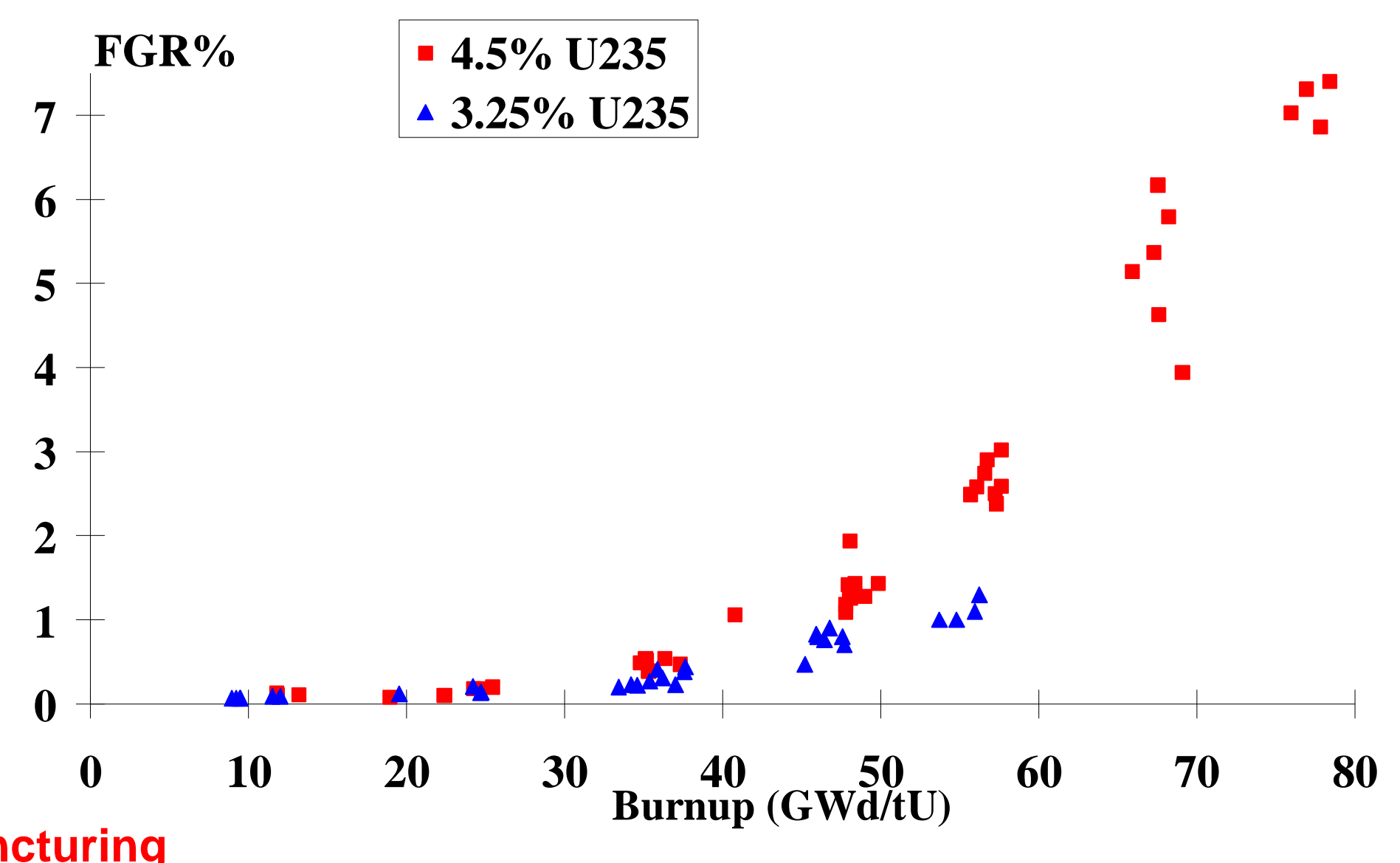

rod puncturing

(NET $2009+$ OECD proc cad 2000) 


\section{cea Increase in the fission gas release rate}

MINDS HBS not the major contributor:

- analyses of the released gas compositions

- direct retention measurements (SIMS +EPMA)

- HBS fully transformed discs Halden IFA 649 for NFIR

(OECD proc cad 2000)

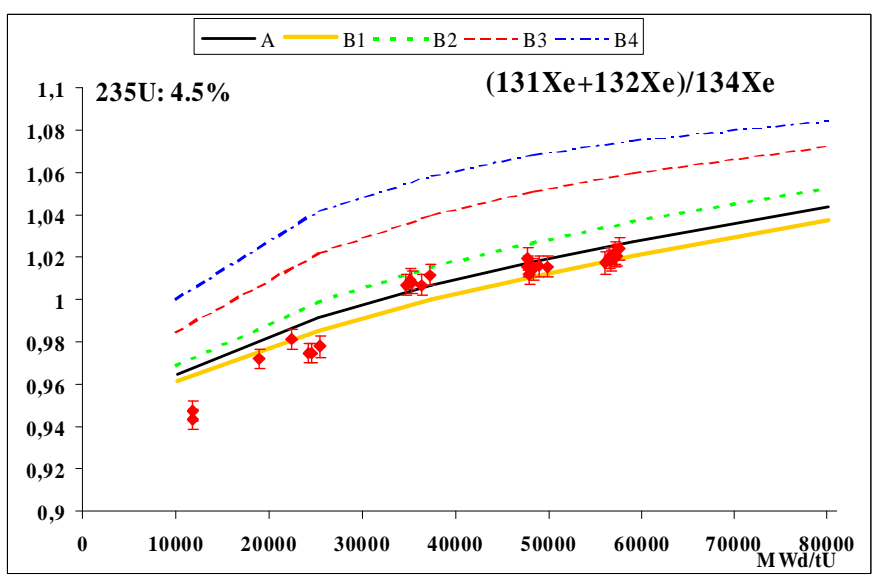

+ (Itagaki 1996)

$+($ Lemoine $2009-\mathrm{MOX})$
(JNM 2008)

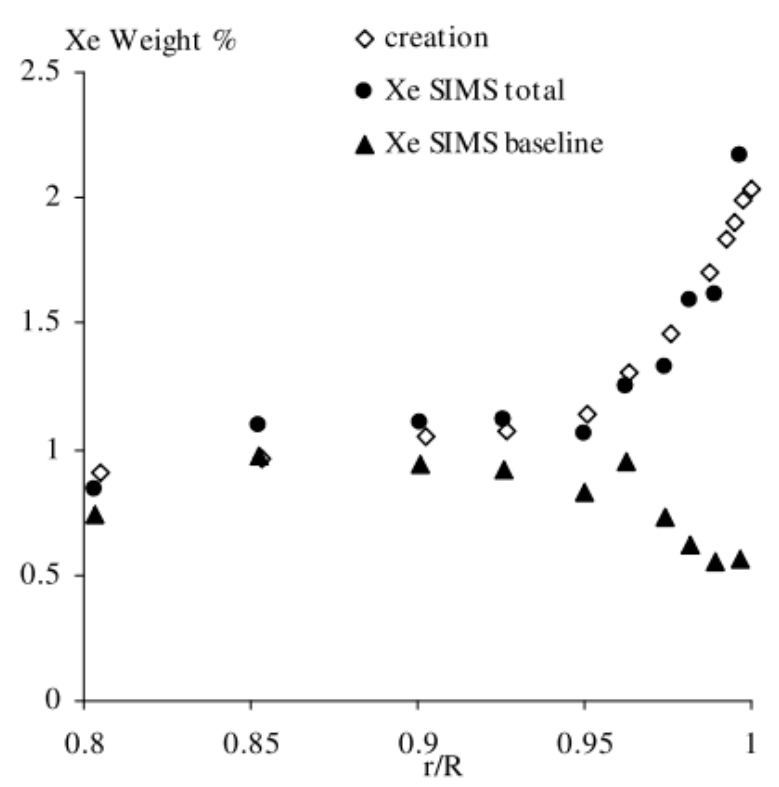

(JNM 2014)

NFIR discs

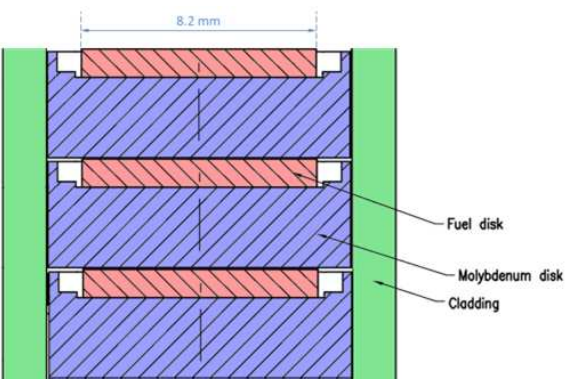

Standard $\mathrm{UO}_{2}$, $103 \mathrm{GWd} / \mathrm{t}_{U}$ Average fission gas release close to $2.9 \%$ of the produced gases for $100 \%$ HBS discs 


\section{cea Increase in the fission gas release rate}

¿MINDS Yet, cracks in the rim $\rightarrow$ gas release
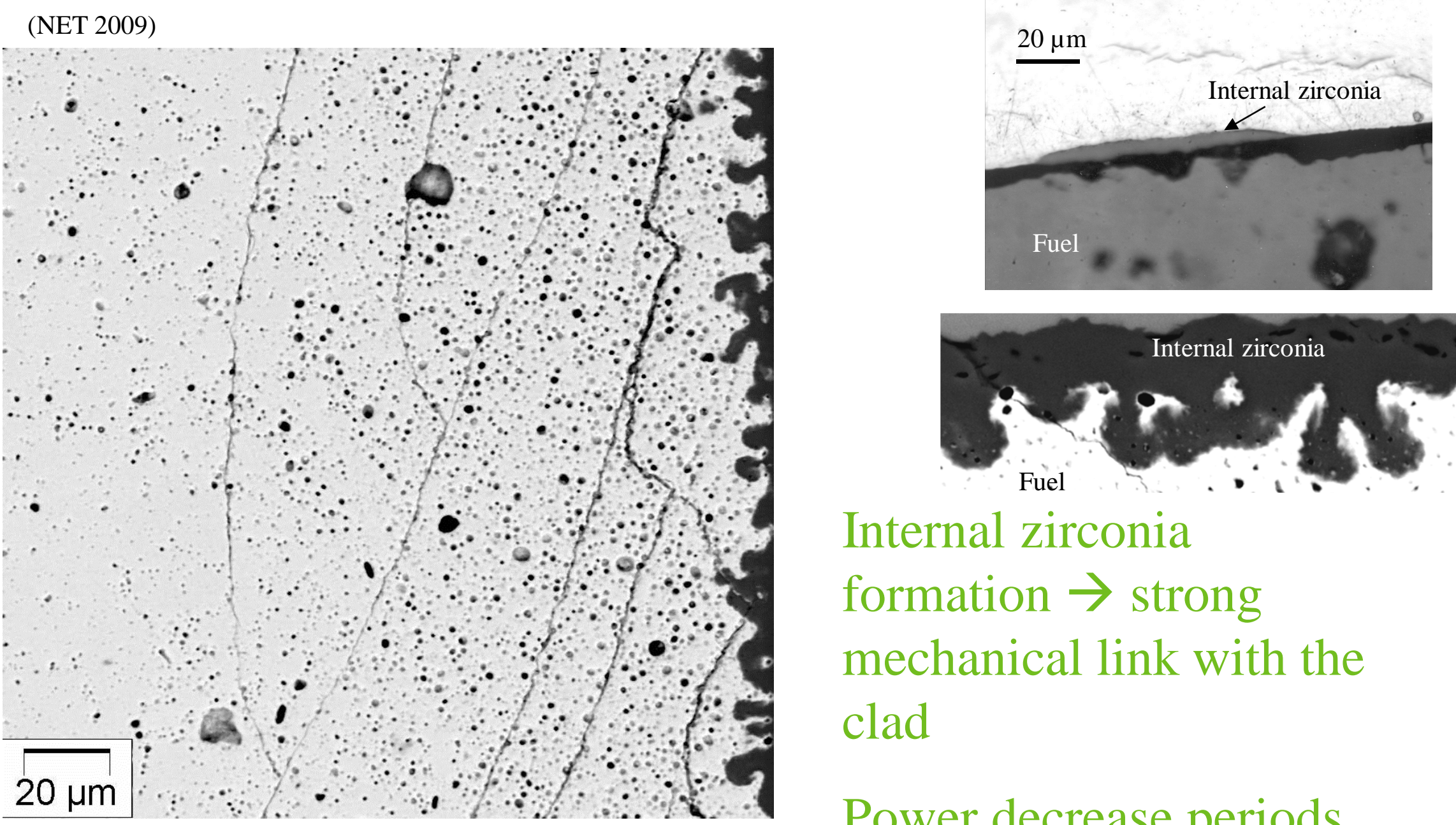

Internal zirconia

formation $\rightarrow$ strong

mechanical link with the clad

Power decrease periods

$83 \mathrm{GWd} / \mathrm{t}_{\mathrm{U}}$

10 


\section{cea Concomitant phenomena}

\section{MINDS}

increase in the fuel swelling

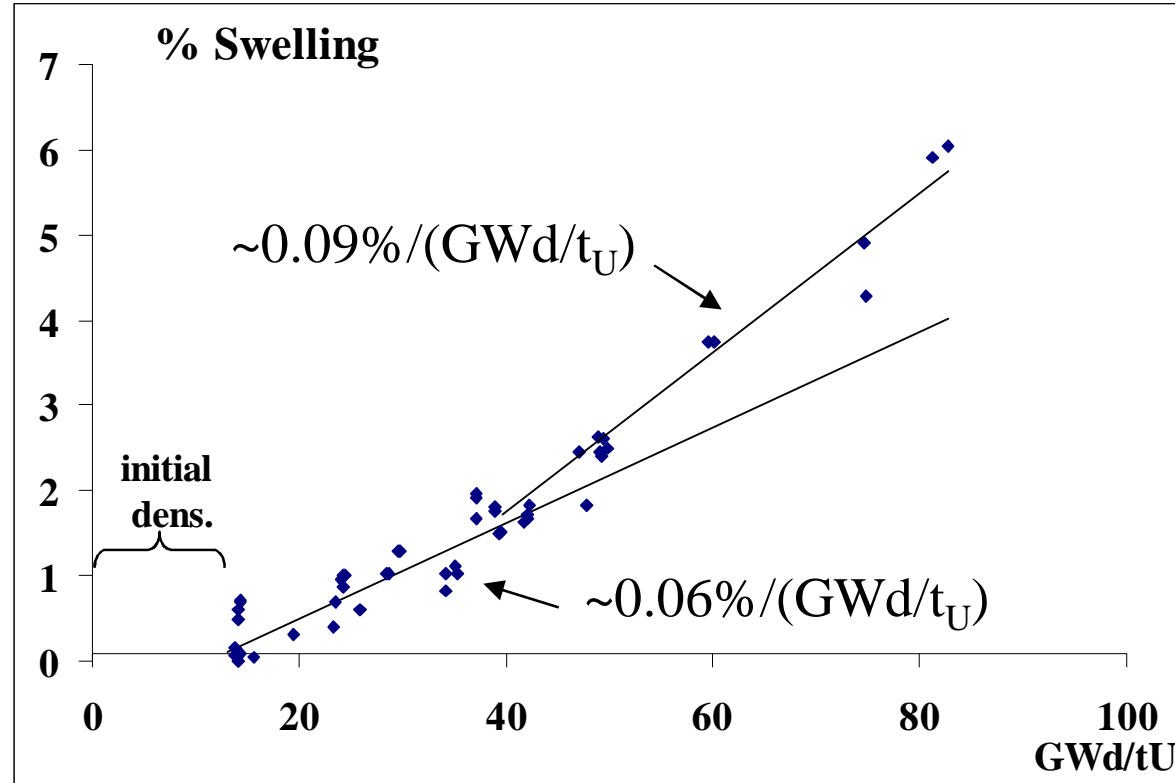

$\mathrm{UO}_{2}$ Fuel swelling in a PWR

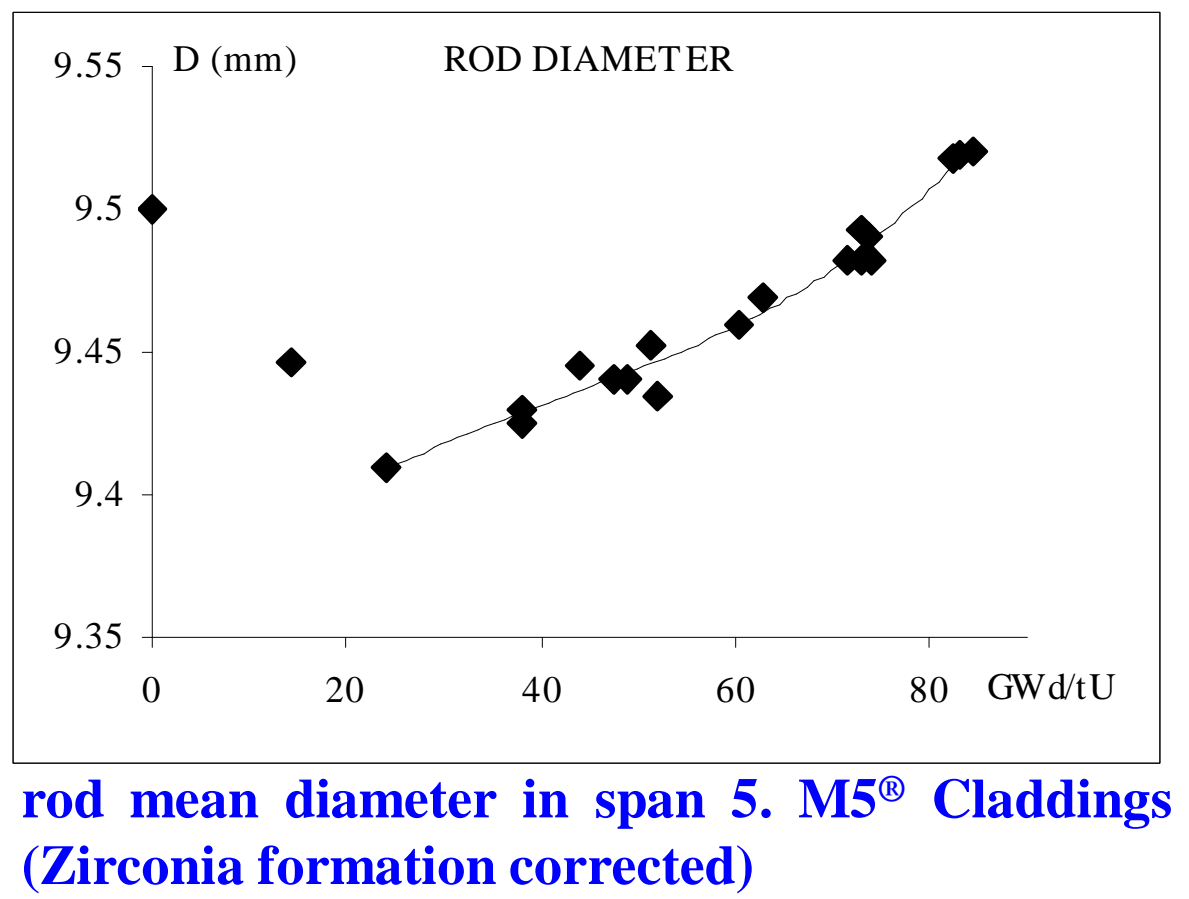




\section{cea Fuel swelling}

¿MINDS HBS only partly responsible for swelling increase
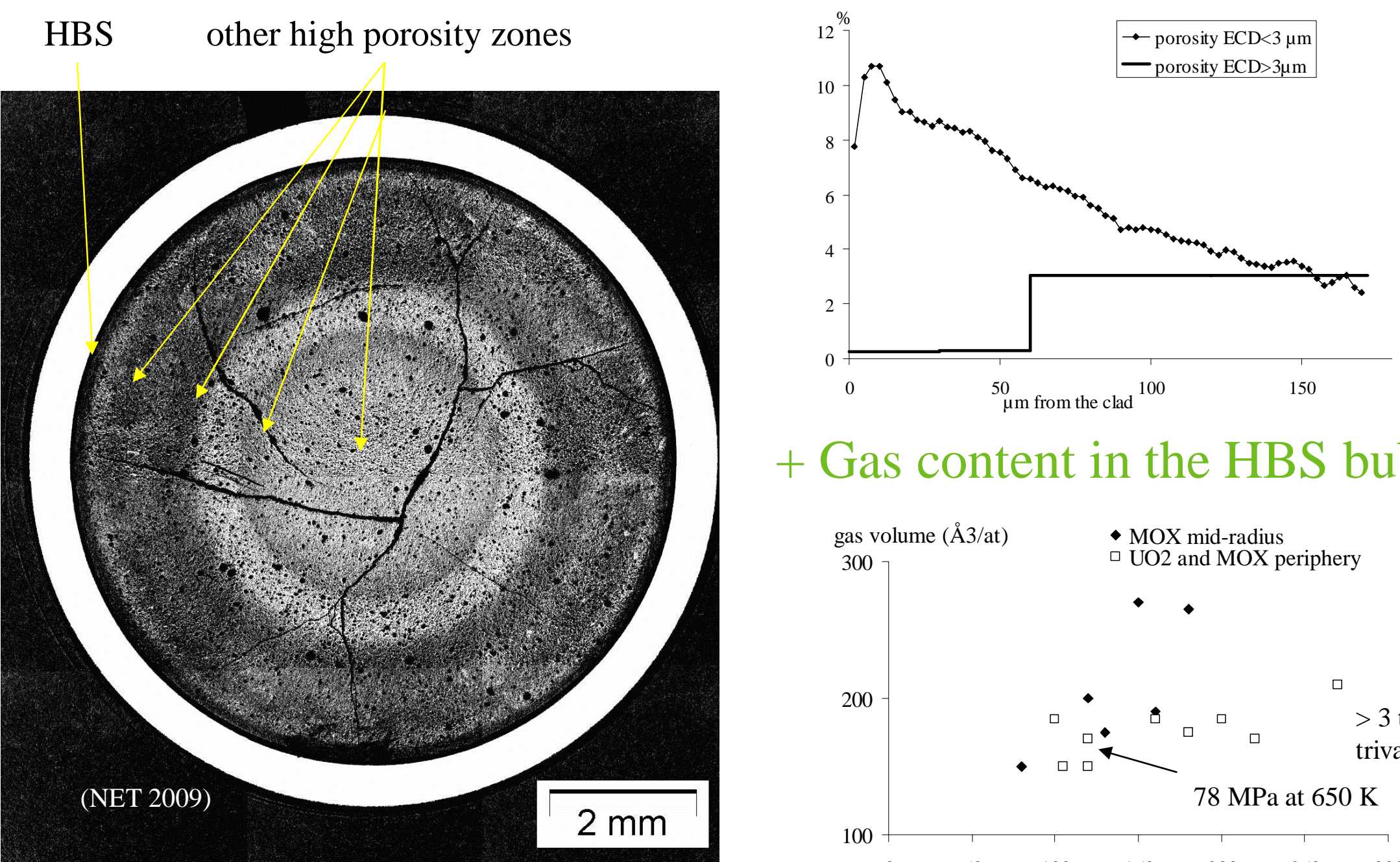

+ Gas content in the HBS bubbles:

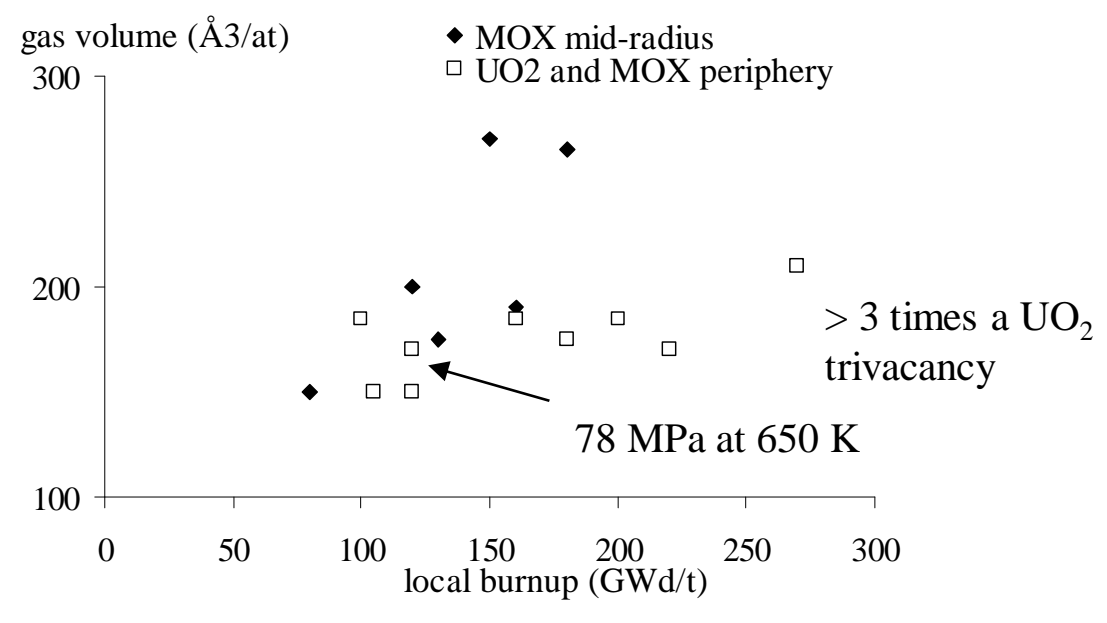

12

$83 \mathrm{GWd} / \mathrm{t}_{\mathrm{U}}$

$2^{\text {nd }}$ Int. MINOS Workshop - November 4-6, 2015, CEA - INSTN Cadarache, France 


\section{cea In lost of coolant situations}

\section{MINDS}

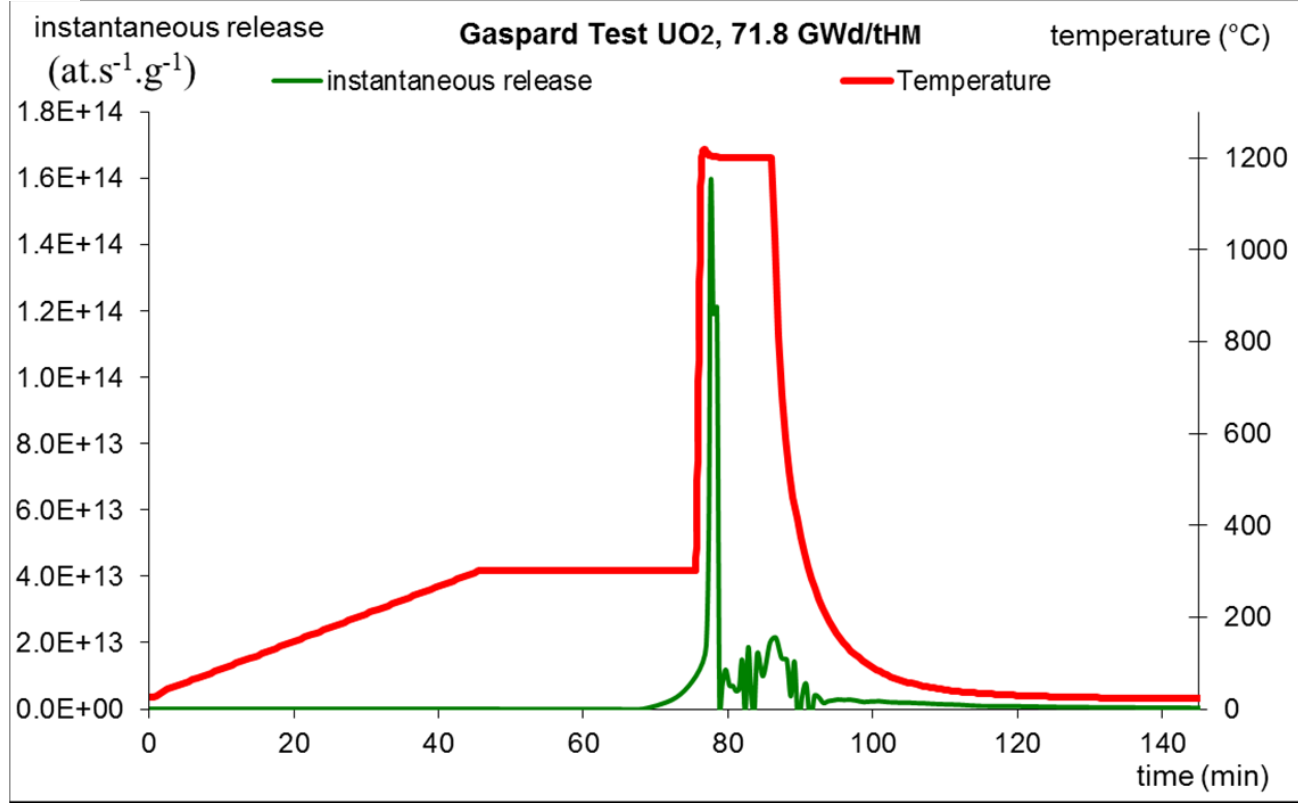

\section{$72 \mathrm{GWd} / \mathrm{t}_{\mathrm{u}}$}

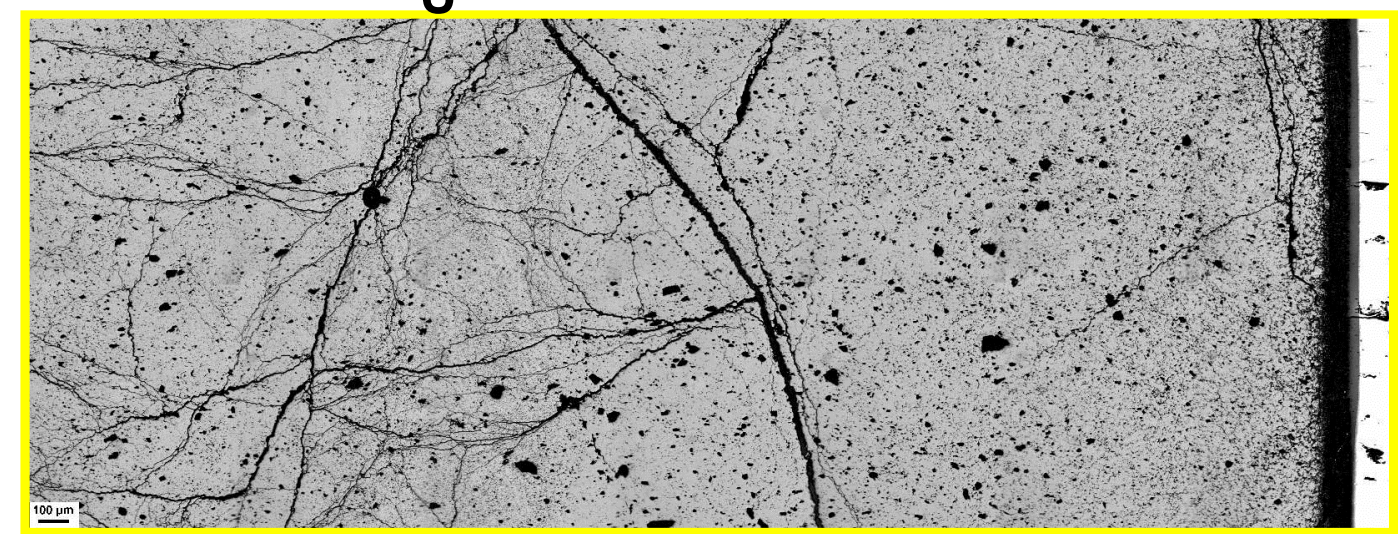

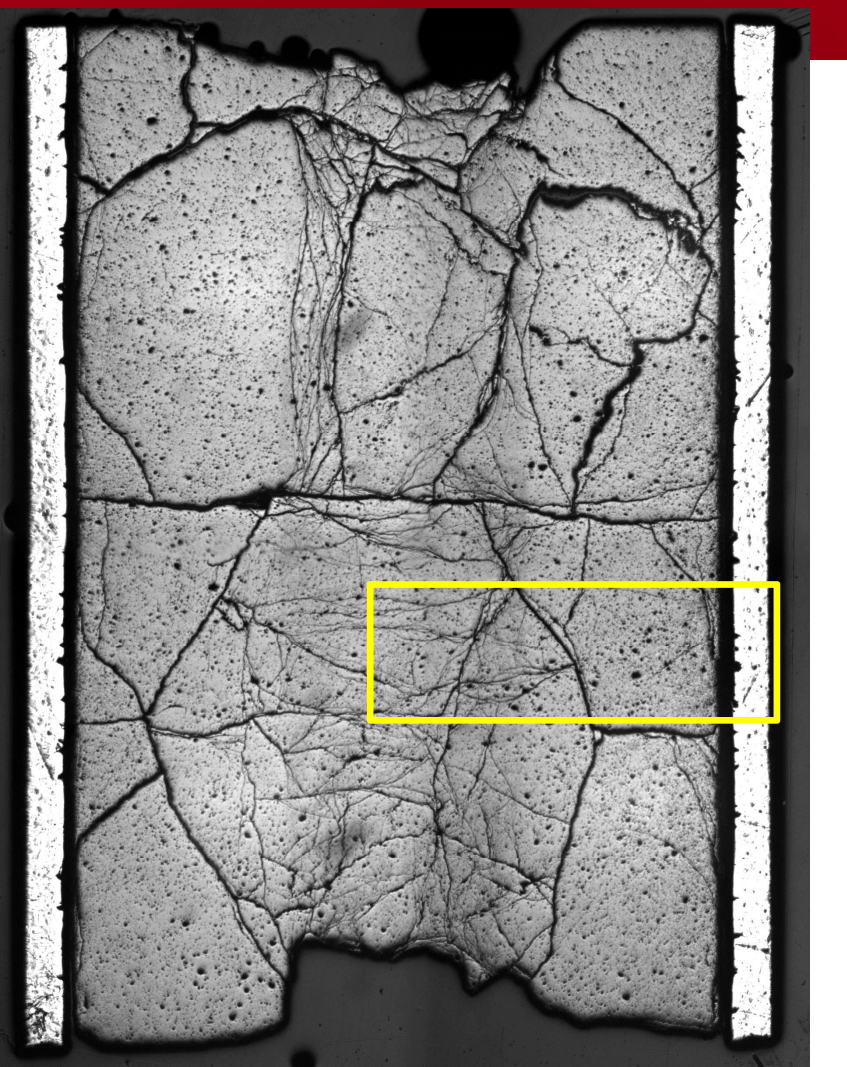

$7006 \%$ \%

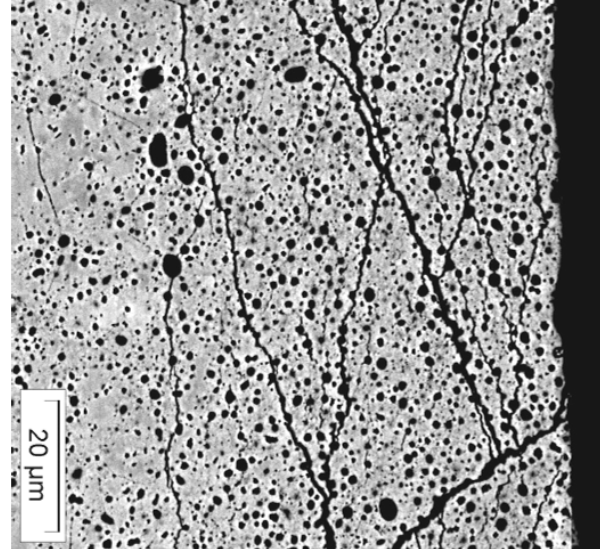




\section{cea In lost of coolant situations}

$\because$ MIN口S
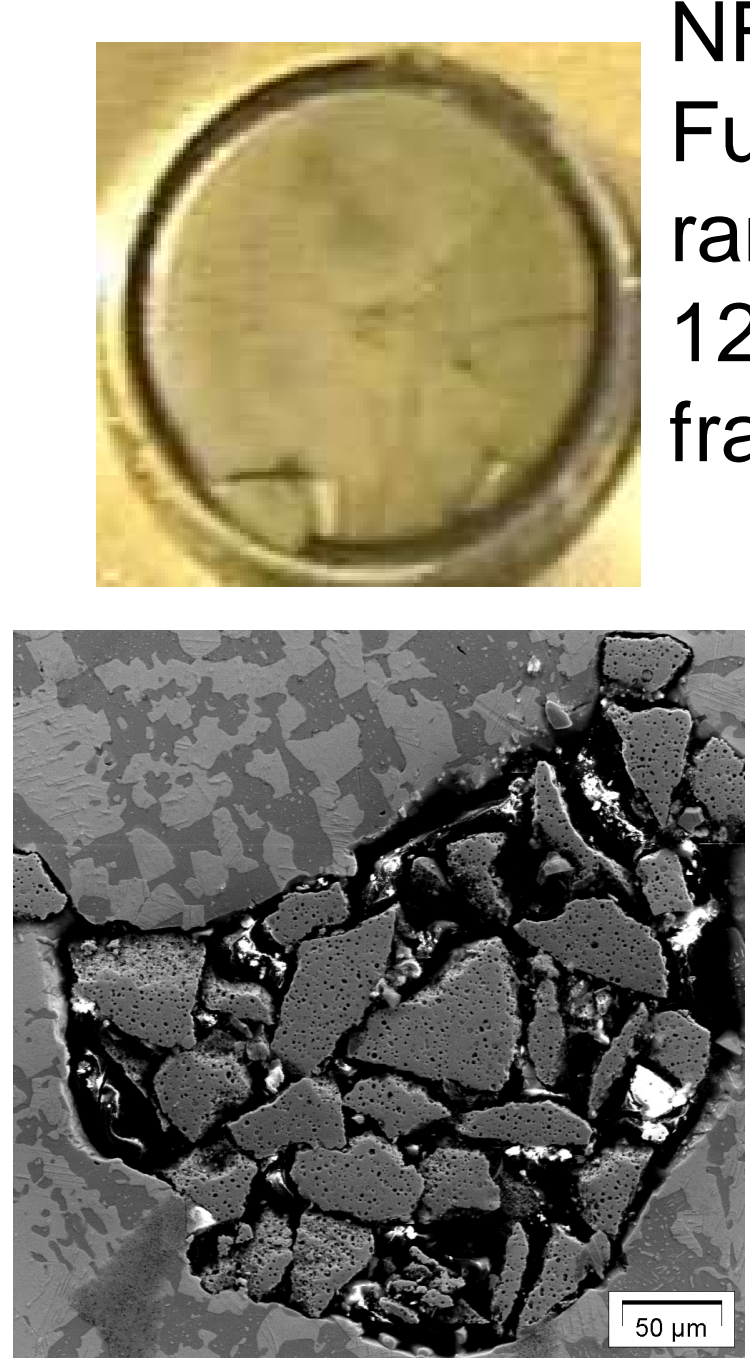

SEM images : Fuel broken into small fragments (JNM 2014)

NFIR

Fully HBS discs ramped at $1200^{\circ} \mathrm{C}$ fragmentation
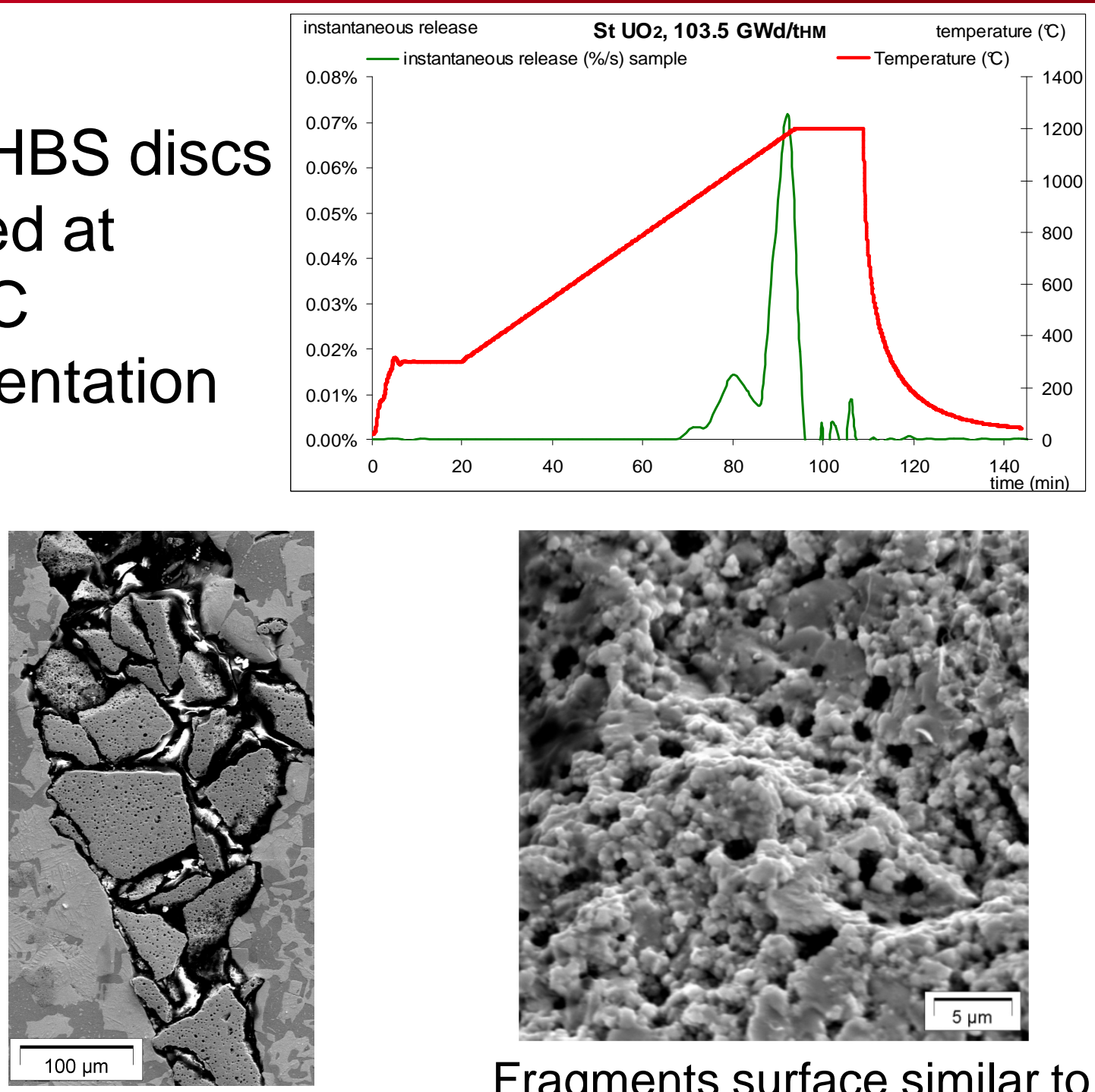

Fragments surface similar to intentionally broken HBS 


\section{cea High BU + heterogeneous + ramp}

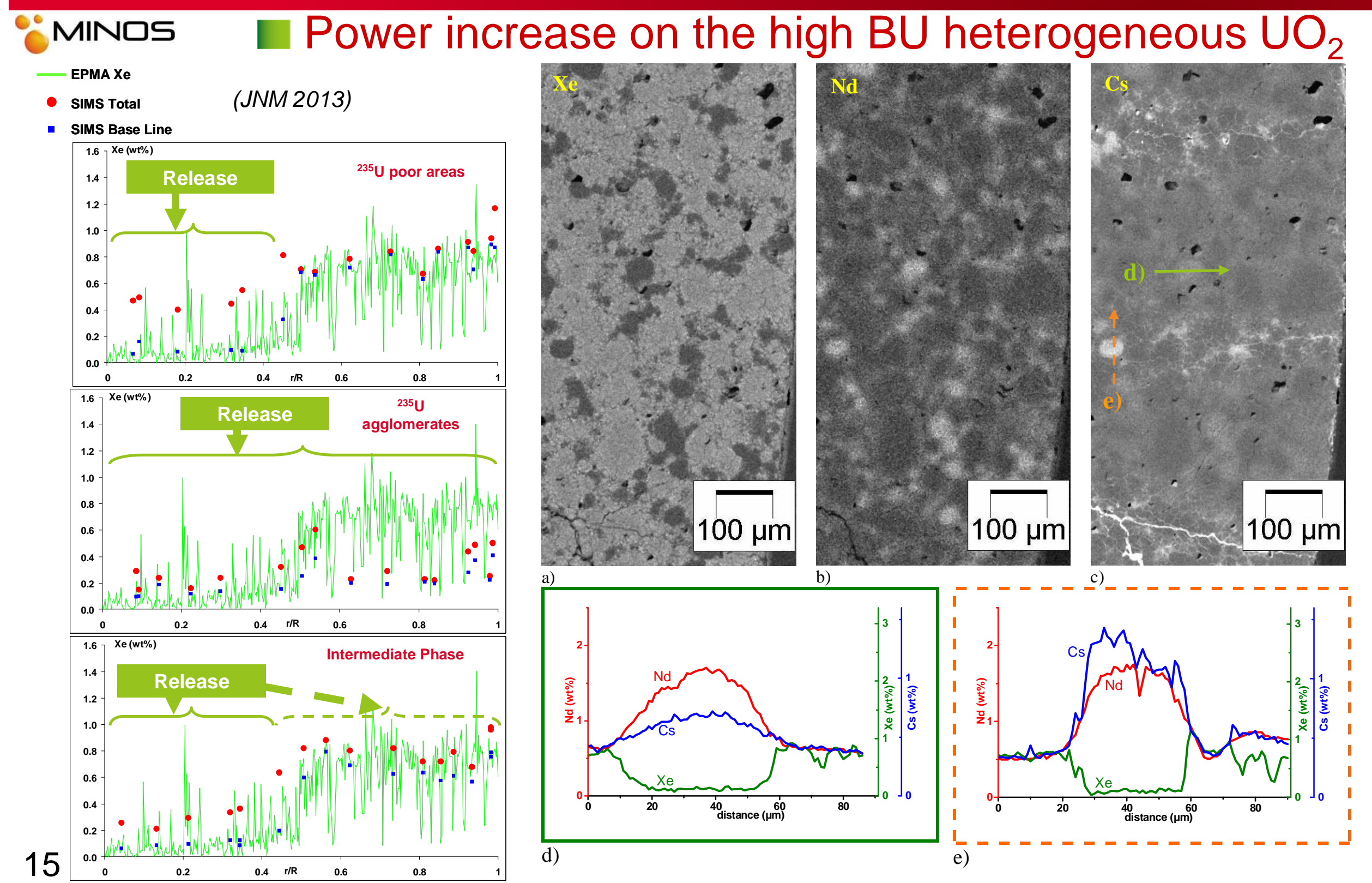




\section{cea Can HBS be avoided in $\mathrm{UO}_{2}$ fuels?}

\section{MINDS NFIR}

Large grain $\mathrm{UO}_{2}$ fabricated without dopant by NFD (Japan)

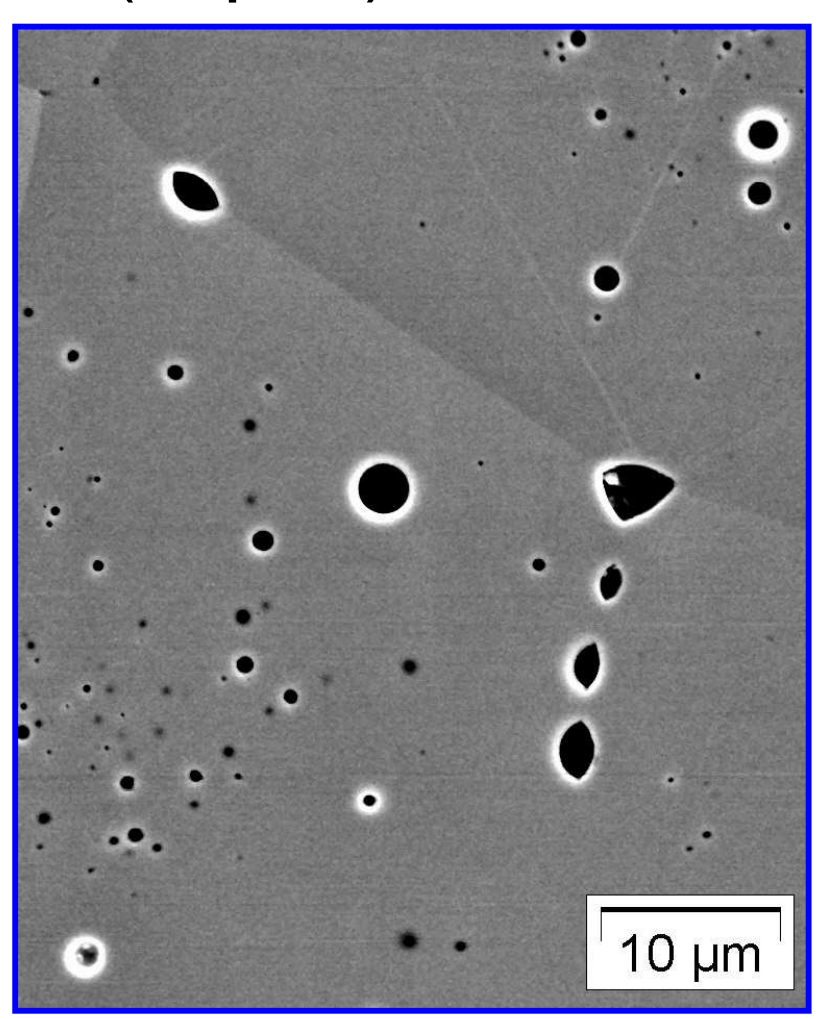

CEA - DEN
At $96 \mathrm{GWd} / \mathrm{t}_{\mathrm{HM}}$ Locally, very high resistance to HBS formation

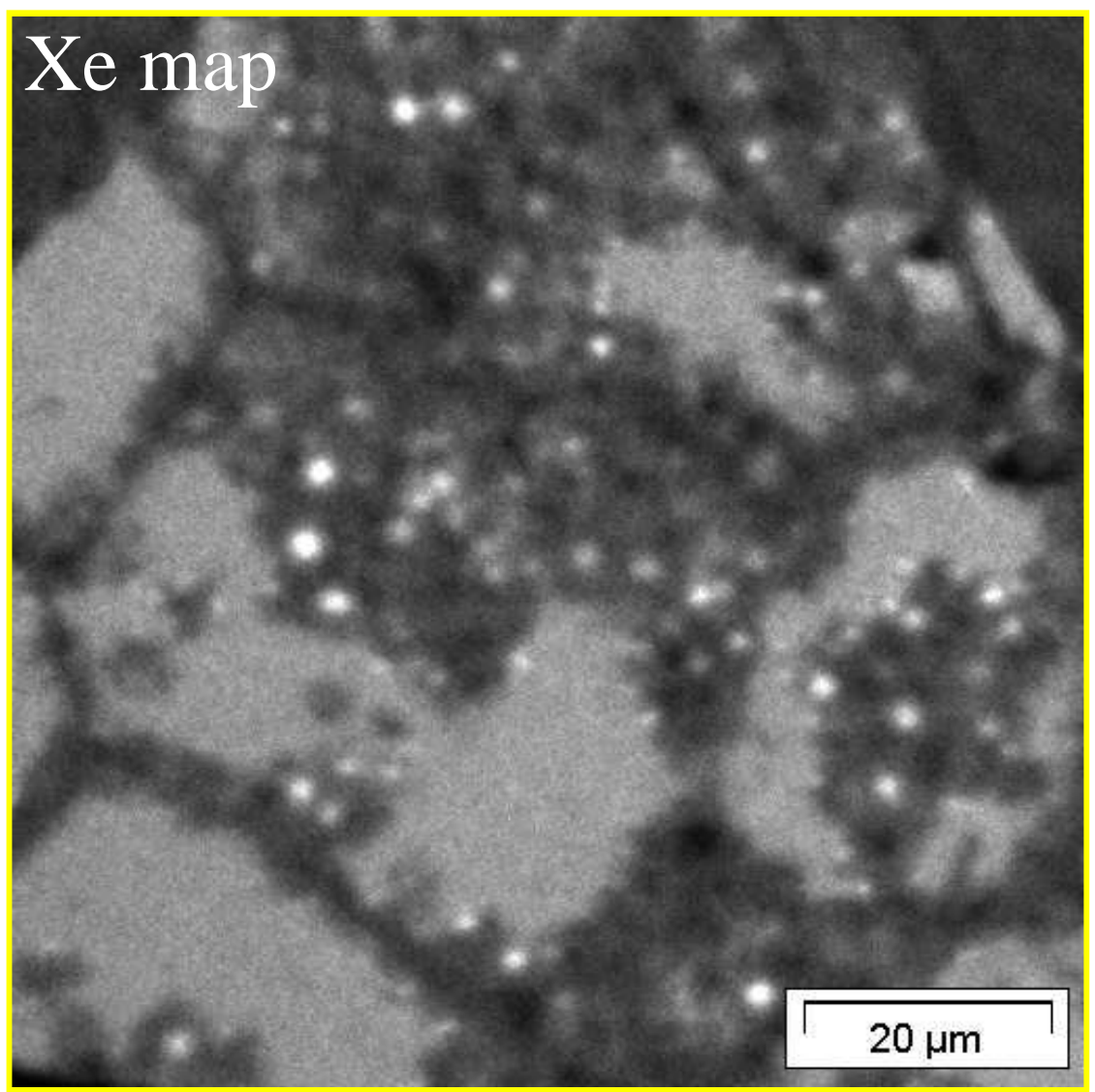

(JNM 2015) 


\section{cea Conclusion}

\section{MINDS}

A research started a few decades ago

- Still progressing

With good hopes on

o the new SEM, + EBSD+FIB+STEM+EDS

o the coming TEM

- MARS beam line at SOLEIL 